\title{
Breeding rate and mortality in Australian parrot (Melopsittacus undulatus) in captivity at Bahawal Pur, Pakistan
}

\author{
Muhammad Zubair Hussain ${ }^{1 *}$, Muhammad Qasim², Ahmad Ali ${ }^{3}$, Syed \\ Qaswar Ali Shah ${ }^{1}$, Seemal Aziz ${ }^{3}$ and Ghulam Mustafa ${ }^{4}$ \\ 1. Department of Zoology, Government Emerson College, Multan-Pakistan \\ 2. Department of Bioinformatics \& Biotechnology, Government College University Faisalabad-Pakistan \\ 3. Department of Life Sciences, Islamia University, Bahawal Pur-Pakistan \\ 4. Department of Fisheries, Bahawal Pur District, Government of the Punjab, Lahore-Pakistan \\ *Corresponding author's email: zubairhussainpk@yahoo.com
}

Citation

Muhammad Zubair Hussain, Muhammad Qasim, Ahmad Ali, Syed Qaswar Ali Shah, Seemal Aziz and Ghulam Mustafa. Breeding rate and mortality in Australian parrot (Melopsittacus undulatus) in captivity at Bahawal Pur, Pakistan. Pure and Applied Biology. Vol. 6, Issue 2, pp511-515. http://dx.doi.org/10.19045/bspab.2017.60051

\begin{tabular}{llll}
\hline \hline Received: 12/01/2017 & Revised: 20/03/2017 & Accepted: 27/03/2017 & Online First: 30/03/2017 \\
\hline \hline
\end{tabular}

\section{Abstract}

The present study was conducted to find out the breeding rate and mortality of Melopsittacus undulatus (budgerigar), a famous species of Australian parrots. A total of 100 birds (50 pairs), kept in a farm house at Bahawal Pur, Pakistan were used in this study. Number of eggs, clutch size, number of hatchings, hatchlings and fledglings were recorded for estimation of breeding rate. Total number of eggs was 537 during whole breeding season. Clutch size varied from 1-9. The hatching and hatchling success was found to be $29.69 \%$ and $81.76 \%$ respectively. The clutch size and number of eggs laid in breeding season were adequate for rapid increase in population. The hatching rate and fledging rate indicated good reproductive success in captivity.

Keywords: Budgerigar; Clutch size; Hatching success; Fledglings

\section{Introduction}

The term "Parrot" generally refers to more than 350 species of the order Psittaciformes, with worldwide distribution [1]. Several species of the parrot family are famous as pets [2]. The budgerigar, Melopsittacus undulatus (Shaw), is a wild parrot in Australia, kept in aviaries throughout the world. It is one of the species of parrots that have self-reproducing captive population and no longer need to be augmented with wild living birds [3].

Knowledge of breeding biology is one of the important aspects for successful farming of the bird species. Reproductive output of captive birds is enough to persuade market demand [4]. There are several studies carried out on several species of parrots that consider reproductive potential of these birds in wild [5-8]. Measuring the routine of nesting attributes such as egg fertility, hatching success, fledging success and reproductive output, allows us to find out the reproductive health of the species and thus helps to understand causes of decline or increase in populations $[9,10]$.

The growing popularity of parrots as pets has led to increased importance in their farming in captivity. In the last two decades, the parrot culture especially of Australian 
parrots has flourished rapidly in Pakistan and getting attraction as a pet business. Therefore studies are required which would contribute to make parrot culture more beneficial. The present study was aimed to determine the clutch size, hatching and hatchling success in parrot species Melopsittacus undulatus in captivity, so as to assess its breeding rate and mortality.

\section{Materials and methods}

Breeding biology and mortality rate of a famous pet species of Australian parrots, the budgerigar (Melopsittacus undulatus) was investigated. The study was conducted at a farm house in Bahawal Pur, Pakistan. The experiment was conducted for duration of six months (November 2014 to April 2015) including a total of 100 birds (50 pairs with equal number of males and females). These birds were provided with artificial nests made by small sized mud pots $(n=50)$, each with two openings to facilitate entrance and exit of birds from nest. Water availability was ensured round the clock. Furthermore, maintenance of proper ventilation, light dark cycle, temperature and cleanliness was regularly monitored.

The data was collected after interval of one day. The fate of each egg was recorded as either lost before hatching, failed to hatch or hatched. Nestlings that disappeared from the nest before reaching fledging age were recorded as deaths. Total number of hatchings, hatchlings and fledglings was recorded. Hatchling success was calculated as follows;

Hatchling success $=$ (number of eggs hatched / number of eggs laid) x 100 .

While fledgling success was calculated a follows;

Fledgling success $=$ (number of fledglings / number of hatchlings) x 100 .

\section{Results}

A total of 537 eggs were recorded during six months of study period. It was observed that maximum number of eggs (141) was laid in March 2015; while minimum number of eggs (43) was recorded in November 2014 (Table 1). The maximum clutch size (9) was observed in March 2015. The maximum percentage i.e. $95 \%$ (41/43) of broken/rotten eggs was observed in November 2014 followed by $84 \%(54 / 64)$ in January 2015 and $72 \%(85 / 118)$ in February 2015. The lowest percentage of broken/rotten eggs i.e. 46.10 (65/141) was recorded in March 2015. The hatching ratio was highest i.e. $37 \%$ (53/141) in March 2014 followed by $36 \%$ $(18 / 49)$ in December 2014 and 35\% (43/122) in April 2015. It was lowest i.e. 4\% (2/43) in November 2014. The fledgling success (ratio of fledglings to hatchlings) was higher $(82 \%)$; while hatchling mortality was low i.e. $18 \%$ during study period (Table $1)$. No adult mortality was observed during study period.

Table 1. Breeding rate and mortality in Australian parrot (Melopsittacus undulatus) in captivity at Bahawal Pur, Pakistan

\begin{tabular}{|c|c|c|c|c|c|c|c|c|c|c|}
\hline \multirow[t]{2}{*}{ Months } & \multirow{2}{*}{$\begin{array}{l}\text { Total } \\
\text { number } \\
\text { of eggs }\end{array}$} & \multirow[t]{2}{*}{$\begin{array}{l}\text { Clutch } \\
\text { size }\end{array}$} & \multicolumn{2}{|c|}{ Rotten Eggs } & \multicolumn{2}{|c|}{ Eggs hatched } & \multicolumn{2}{|c|}{$\begin{array}{l}\text { Hatchlings } \\
\text { died }\end{array}$} & \multicolumn{2}{|c|}{ Fledglings* } \\
\hline & & & $\neq$ & $\%$ & $\neq$ & $\%$ & $\neq$ & $\%$ & $\neq$ & $\%$ \\
\hline Nov. 2014 & 43 & $1-5$ & 41 & 95.34 & 2 & 4.65 & 0 & 0 & 2 & 100 \\
\hline Dec. 2014 & 49 & $1-5$ & 29 & 59.18 & 18 & 36.73 & 4 & 22.22 & 14 & 77.78 \\
\hline Jan. 2014 & 64 & $1-5$ & 54 & 84.38 & 10 & 15.63 & 1 & 10 & 09 & 90 \\
\hline Feb. 2014 & 118 & $1-7$ & 85 & 72.03 & 33 & 27.97 & 3 & 9.09 & 30 & 90.91 \\
\hline Mar. 2014 & 141 & $1-9$ & 65 & 46.10 & 53 & 37.59 & 14 & 26.42 & 39 & 73.58 \\
\hline Apr. 2014 & 122 & $1-8$ & 79 & 64.75 & 43 & 35.25 & 07 & 16.28 & 36 & 83.72 \\
\hline & 537 & & 312 & & 159 & & 29 & & 130 & \\
\hline
\end{tabular}

$\neq=$ Number, $\%=$ percentage, $*=$ no adult mortality was observed during study. Total number of birds $=100$ 


\section{Discussion}

In present study, the breeding season for budgerigar (Melopsittacus undulates) lasted from November 2014 to April 2015 (6 month) in captivity; however in another study for the same species of Australian parrot carried out in wild, breeding season lasted from September to February [5]. These differences in onset of breeding season may be due to differences in climatic conditions or may be due to captivity or wildness. The breeding season is attributed to be primarily controlled by photoperiod [11] while other secondary environmental factors like temperature and food supply may also have influence on initiation of egglaying period [11, 12]. Still in some other species of parrots, breeding season lasted from October to January for monk parakeet [11], and from March to May for Roseringed parakeets [8]. Such difference may be due to differences in species.

The eggs were laid on daily basis or on alternate days. This is consistent with other studies on other species of parrots including neotropical parrots [6] and black cheeked Lovebird [13]. In our study, clutch size varied from 1-9. Clutch size ranged up to 7 in the same species in wild [5], however, it slightly varies in several species of parrots. It ranged up to 7 in red crowned parakeets [7] and Rose-ringed parakeets [8], up to 8 in black cheeked Lovebird [13] and in thick billed parrots [14], up to 12 in monk parakeet [15].

Clutch size tends to be conserved within clades and often co-varies with biological attributes such as body size, nestling development, nest type as well as feeding rate and frequency of females [16]. There are also several environmental factors influencing clutch size, which may vary with respect to latitude $[17,18]$, gradients of resource availability, seasonality [19, 20], variations in rainfall [21] and between biogeographic regions.
The results of our study demonstrated that incubation started with the first egg and incubation period lasted for 22-25 days, while it lasted for 18-20 days in budgerigar in wild [5]. This slight variation in incubation period could be due to differences in climatic conditions or due to wildness and captivity. This observation about duration of incubation is also consistent with other studies in several other species of parrots including 21 days in Roseringed parakeets [8], 22 days in black cheeked Lovebird [13] and 23 days in monk parakeet [15].

In our study, the hatching success was at the maximum (37.59\%) in March 2015. While, total hatching success was $29.61 \%$. However, several other workers have reported different percentages of hatching success like $70 \%$ in black cheeked Lovebird [13], 79\% in thin billed parrots [14] and $52.2 \%$ in monk parakeet [15]. Several factors have been identified as probable causes of egg failure to hatch in wild studies. These include infertile or unviable eggs, nest abandonment, predation and human disturbance [21]. Hatching success may also be influenced by infection and temperature [22].

The results of our study demonstrated that chicks fledged out at 30-38 days; consistent with several other studies in parrots like 2835 days in neotropical parrots [6], 30-40 days in black cheeked Lovebird [13]. In our study, the fledgling success was $81.76 \%$ during study period, while $40 \%$ has been reported in budgerigar in wild habitat [5]. The results from other studies indicate lower hatchling success. Only $17 \%$ of the nestlings fledged in monk parakeet [15]. Generally, mortality of fledgling appears to be high in psittaciform birds [23]. However, in present study fledgling mortality was low. This may be due to the reason that some of the important factors (e.g. predation or food 
deprivation) to cause mortality were not acting in captivity.

\section{Conclusions}

Australian parrots after adolescence starts laying eggs on daily basis or alternate days with a clutch size from 1-9. The incubation started when the first egg was laid and lasts up to 22-25 days. The clutch size and number of eggs laid in breeding season were adequate for rapid increase in population. The hatching rate and fledging rate indicated good reproductive success in captivity. The fledgling period consist of 30-38 days.

\section{Authors' contributions}

Conceived and designed the experiments: A Ali \& G Mustafa; Performed the experiments: S Aziz \& G Mustafa; Analyzed the data: MZ Hussain, SQA Shah \& A Ali; Contributed reagents/ materials/ analysis tools: A Ali \& G Mustafa; Wrote the paper: MZ Hussain, SQA Shah, A Ali, M Qasim \& S Aziz.

\section{References}

1. Snyder N (2000). Parrots. Status Survey and Conservation Action Plan 20002004. IUCN: Gland, Switzerland and Cambridge, UK.

2. Gill FB (1990). Ornithology, 2nd Ed. WH Freeman and Company: New York, USA.

3. Juniper T \& Parr M (1998). Prrots: A guide to the parrots of the world. Pica Press East Sussex, UK.

4. Derrickson SR \& Synder NFR (1992). Potentials and limits of captive breeding in parrot conservation. In: New World Parrots in crisis. Beissinger SR, Synder NFR, editors. Wasington DC. Smithsonian Institution Press. pp.133-163.

5. Wyndham E (1980). Diurnal cycle, behavior and social organization of the Budgerigar (Melopsittacus undulatus). Ети. 80: 25-33.

6. Beissinger SR \& Waltman JR (1991). Extraordinary clutch size and hatching asynchrony in a neotropical parrot. $A u k$ 108: 863-871.

7. Greene TC (2003). Breeding biology of red crowned parakeet (Cyanoramphus novaezelandiae novaezelandiae) on Little Barrier Island, Hauraki Gulf, New Zealand. The Ornithological Society of New Zealand. Notornis 50: 83-99.

8. Butler CJ, Creswell W, Gosler A \& Perrins C (2013). The Breeding Biology of Ring-rose parakeet (Psittacula krameri) in England during a period of rapid population expansion. Bird Study 60: 527-532.

9. Newton I (1998). Population limitations in birds. Academic Press London.

10. Green RE (2004). Breeding Biology. In: Bird ecology and conservation - a handbook of techniques. SutherLand WJ, Newton I, Green RE, editors. Oxford University Press New York. pp. 57-83.

11. Novarro JL, Martella BM \& Bucher EH (1992). Breeding season and productivity of monk parakeets in Cordoba, Argentina. Wilson Bull Argentina 104: 413-424.

12. Møller AP (2013). Biological consequences of global change for birds. Integr Zool 8: 136-144.

13. Warburton LS \& Perrin MR (2005). Nest-site characteristics and breeding biology of the Black cheeked Love Bird (Agaporni nigrigenis) in Zambia. Ostrich 76: 162-174.

14. Monterrubio T, Enkerlin-Hoeflich E \& Hamilton RB (2002). Productivity and nesting success of thick billed parrots. Condor 104: 788-794.

15. Peris SJ \& Arambura RM (1995). Reproductive phenology and breeding success of the Monk parakeet (Myiopsitta monachus monachus) in Argentina. Studies on Neotropical Fauna and Environment 30: 115-119. 
16. Waltman JR \& Beissinger SR (1992). Breeding behavior of the GreenRumped parrotlet. Wilson Bull 104: 65-84.

17. Cardillo M (2002). The life-history basis of latitudinal diversity gradients: how do species traits vary from the poles to the equator? J Anim Ecol 71: 79-87.

18. Moreau RM (1994). Clutch size: a comparative study, with special reference to African birds. Ibis 86: 286-347.

19. Evans KL, Duncan RP, Blackburn TM \& Crick HQP (2005). Investigating geographic variation in clutch size using a natural experiment. Functional Ecol 19: 616-624.

20. Humphrey QP, David C, Gibbons W \& Magrath RD (1993). Seasonal changes in clutch size in British birds. J Anim Ecol 62: 263-273.
21. Sanz V \& Rodri Guez-Ferraro A (2006). Reproductive parameters and productivity of the yellow-shouldered parrot of Margarita Island, Venezuela: A long-term study. Condor 108: 178192.

22. Stoleson SH (1999). The importance of the early onset of incubation for the maintenance of egg viability. In: Proceedings of the 22nd International Ornithological Congress, Durban, 1997. Adams NJ, Slotow RH, editors. Johannesburg: Bird Life South Africa. pp. 600-613.

23. Robinet O \& Salas M (1999). Reproductive biology of the endangered Ouvea Parakeet Eunymphicus cornutus uvaeensis. Ibis 141: 660-669. 